\title{
Review of Advanced Methods for Treating Radioactive Contaminated Water
}

\author{
M. DUBOURG*
}

(Manuscrit reçu le 22 avril 1997, révisé le 9 juillet 1997, accepté le 20 octobre 1997)

ABSTRACT The accidental release of large quantities of radionuclide after a nuclear accident tends to contaminate the groundwater system of rivers and lakes by the transfer of the main radionuclides such as Cesium 137, Strontium 90 or Cobalt 60, Ruthenium 106 and others (including transuranic radionuclides, such as: ${ }^{239} \mathrm{Pu},{ }^{240} \mathrm{Pu},{ }^{241} \mathrm{Am}$...). The aim of this paper is to review the possible solutions for the removal of these contaminants from large quantities of water. i) The use of crown ethers for the selective removal of strontium 90 such as the dicyclohexyl 18-crown 6 which is able to remove with $90 \%$ of efficiency the Strontium. ii) The use of zeolithes for the removal of Cesium 137. On larger scale the use of electromagnetic filtration technology is able to process in a relatively short time large quantities of water by using a seeding system of resin coated metallic magnetic particles to enhance the filtering efficiency under cold conditions. Examples of efficiencies and results obtained on loops at a fairly large scale will be given in this paper, these examples show rather high efficiency of removal even at low concentration of contaminants (a few ppb: part per billion). Examples of water treatment concepts will be also given for treatment of contaminated surface water and to treat large groundwater applications. Major applications could be implemented on various sites namely in Russia (Karatchaï lake) or in Belarus and Ukraine. The magnetic filtration is not a new concept but with the use of various selective adsorbing treatment particles, this concept has been proven so effective that dissolved metals in process water have been reduced to level in the very low ppb range.

RÉSUMÉ Examen des méthodes avancées de traitement de l'eau radioactive contaminée à la suite d'accidents nucléaires.

Le relâchement accidentel de grandes quantités de radionucléides après un accident nucléaire provoque la contamination des rivières et des lacs, par le transfert des principaux radionucléides, tel que le césium 137, le strontium 90 ou le cobalt 60, le ruthénium 106 et d'autres, notamment les transuraniens : uranium, plutonium, américium. $L$ 'objet de cet article est d'examiner les solutions possibles pour l'extraction de ces contaminants radioactifs à longue période de décroissance de grands volumes d'eau. i) L'utilisation des éthers couronne pour l'extraction sélective du strontium 90 tel que le dicyclohexyl 18-6 est capable d'extraire avec une efficacité de $90 \%$ les isotopes du strontium. ii) $L$ 'utilisation des zéolithes pour l'extraction du césium 137. iii) Enfin des essais mettant en ouvre des résines inorganiques à base d'hexacyanoferrate de cobalt potassium ont montré l'excellente capacité d'absorption du césium radioactif. L'utilisation à grande échelle de la technologie de la filtration électromagnétique permet de traiter en un temps court de grands volumes d'eau en inséminant l'eau à traiter de résines enrobant des particules magnétiques qui prmet une fixation des contaminants radioactifs sur la matrice magnétique du filtre électro-magnétique. 
Cette insémination par des particules magnétiques microscopiques renforce l'efficacité de rétention du filtre électromagnétique. Des exemples d'efficacité et des résultats obtenus lors d'essais en boucle à grande échelle sont indiqués dans ce document. On constate que des efficacités de rétention de $80-90 \%$ peuvent être mesurées, même avec de très faibles concentrations en polluants radioactifs (quelques ppb: parties par milliard). Les concepts des traitements décrits pourraient être appliqués au traitement des eaux contaminées en surface et à la dépollution des eaux souterraines. Ces applications pourraient s'adapter aux sites de Chernobyl en Ukraine (réservoir de refroidissement de la centrale et rivières voisines), et à certains sites pollués du complexe militaro-industriel de la fédération de Russie, tel que le site de Mayak et le lac Karatchaï en Sibérie occidentale. La filtration magnétique n'est pas un concept nouveau, mais son utilisation avec des particules très sélectives pour l'absorption des contaminants radioactifs, peut permettre la résolution des problèmes sévères de pollution radioactive à grande échelle, résultant des accidents nucléaires graves. Des installations mobiles peuvent être envisagées pour traiter et assainir des eaux contaminées par des pollutions préalablement identifiées en terme de radionucléides ou de métaux lourds.

\section{Problem definition}

In the case of a nuclear accident, the fallout of radionuclides dispersed by the accident tends to contaminate the environment and mainly the rivers and the water systems.

For instance at Chernobyl (Ukraine), the main reservoirs located near the crippled Unit $n^{\circ} 4$ are heavily contaminated by various radionuclides having a large decay half life such as:

- Cesium 137 Half life : 30 years

- Strontium 90 Half life : 28 years

- Fuel debris containing Uranium, Plutonium, Americium - the half life of these radionuclides goes from 450 years to nearly infinity.

Concerning the Chernobyl sarcophagus, the effects of rain precipitation which is falling onto the top of the sarcophagus at a rate of 10000 cubic meters per year. In addition routine spraying for preventing the dust release outside, the sarcophagus has generated about 3000 cubic meters of water inside the sarcophagus which is contaminated by gamma emitters at an estimated value of $2 \times 10^{8}$ bequerels per liter.

The Kurchatov Institute estimates that the treatment of the groundwater in the area is more acute because up to 700 kilograms of nuclear fuel material are buried in the ground on the plant site, and an additional $3000 \mathrm{~kg}$ are distributed outside the evacuated $30 \mathrm{~km}$ zone, around the Chernobyl site.

Due to the explosion of a tank containing high level waste in the Southern Urals, large radioactive releases were sent to the Karatchaï lake. An artificial 
open air of radioactive waste (containing about $4 \times 10^{18}$ Bequerels) covering an area of $0.5 \mathrm{~km}^{2}$ and known as lake Karachai, has thus been created.

Moreover, the Techa river was used as a discharge means of effluents generated by the Mayak reprocessing complex in the southern Urals.

Analysis of the water of this river has been made for measuring the activity of both the water and sediments by russian and german laboratories.

The Table I gives the main results of specific activity which shows that the major part of the activity is now in the sediment and in the soil near the Techa river banks.

TABLE I

Measurements of activity near the Techa river.

Mesure de l'activité au voisinage de la rivière Techa près de l'usine Mayak.

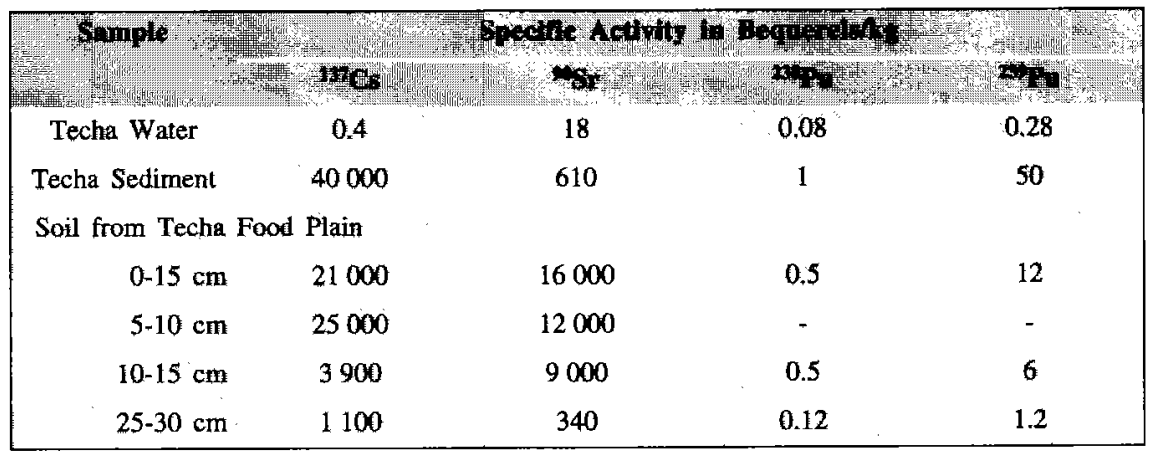

This table shows that it is important to treat and to decontaminate the water in order to avoid an heavy contamination of sediments and of embankments.

Typical dose rate generated by the embankment of the Techa River is $5 \mu \mathrm{Sv} / \mathrm{h}(5$ micro Sievert per hour) which is about 200 times the normal back-ground.

\section{Solutions for selective extraction of radionuclides}

In contaminated water, the three main radionuclides to be removed are:

- the Caesium

- the Strontium

- and the fuel particles which include uranium plutonium and americium after a certain time of radioactive decay.

\subsection{Removal of Caesium}

Because of its relatively long half life (30 years) and high fission yield ${ }^{137} \mathrm{Cs}$ is the major radioactive component in most low and intermediate - active 
nuclear waste solutions - Separation of ${ }^{137} \mathrm{Cs}$ from these solutions would substantially reduce their activity, in many cases to a level enabling discharge of the residual solutions. Inorganic ion exchangers are useful materials for this kind of separation processes, because they often exhibit high selectivities for specific metal ions. Zeolites are being used for the separation of Cesium from low and intermediate waste solution at nuclear power plant and fuel reprocessing plants. Zeolites have been extensively used for the decontamination of released water during TMI 2 accident in the USA in 1979.

For Cesium the best absorption properties have been shown by hexacyanoferrate. Potassium cobalt hexacyanoferrate has been tested in laboratory, the resulting product had a composition of:

$$
\mathrm{K}_{1.8} \mathrm{Co}_{1.1} \mathrm{Fe}(\mathrm{CN})_{1.4}^{6} \mathrm{H}_{2} \mathrm{O}
$$

granulates suitable for column operations can be obtained by grinding the dried cake from precipitation of the hexacyanoferrate.

The typical treatment system is given in the Figure 1.

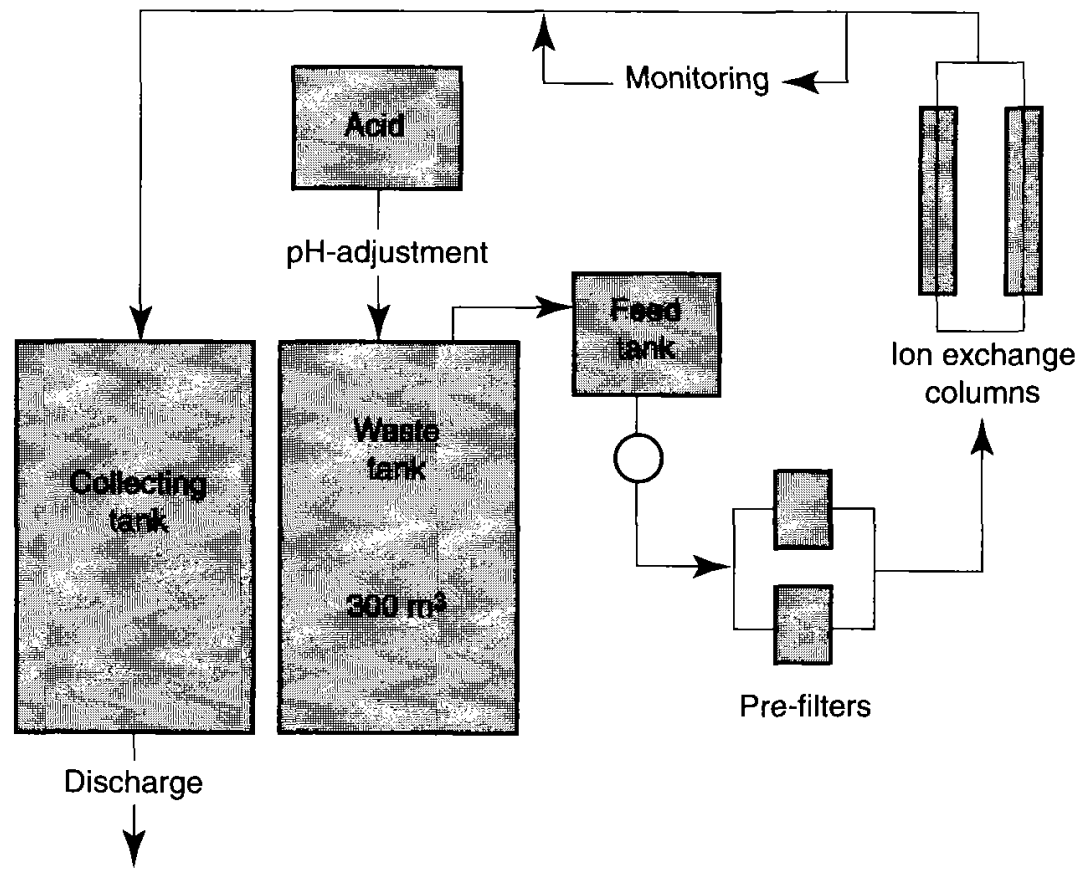

Fig. 1. - Flow sheet of a Cesium separation unit.

Diagramme d'une unité de séparation du cesium. 
The system consists of:

- a collecting tank containing the radioactive liquid waste

- a pH adjustment with $\mathrm{NO}_{3} \mathrm{H}$ in order to adjust the $\mathrm{pH}$ of the solution

- a series of prefilter

- a packed bed containing hexacyanoferrate granulates in a stainless steel shielded canister.

After monitoring the discharge activity the effluent treated can be release to the environment.

An illustration of performance is given in the Figure 2 which indicates the decontamination factor obtained for processing about $180 \mathrm{~m}^{3}$ on a column containing 8 liters of potassium cobalt hexacyanoferrate at a flow rate of $801 / \mathrm{h}$.

The decontamination factor is in the range of $3000-4000$ and the activity removed is concentrated on a 8 liter volume of granulates in a shielded canister.

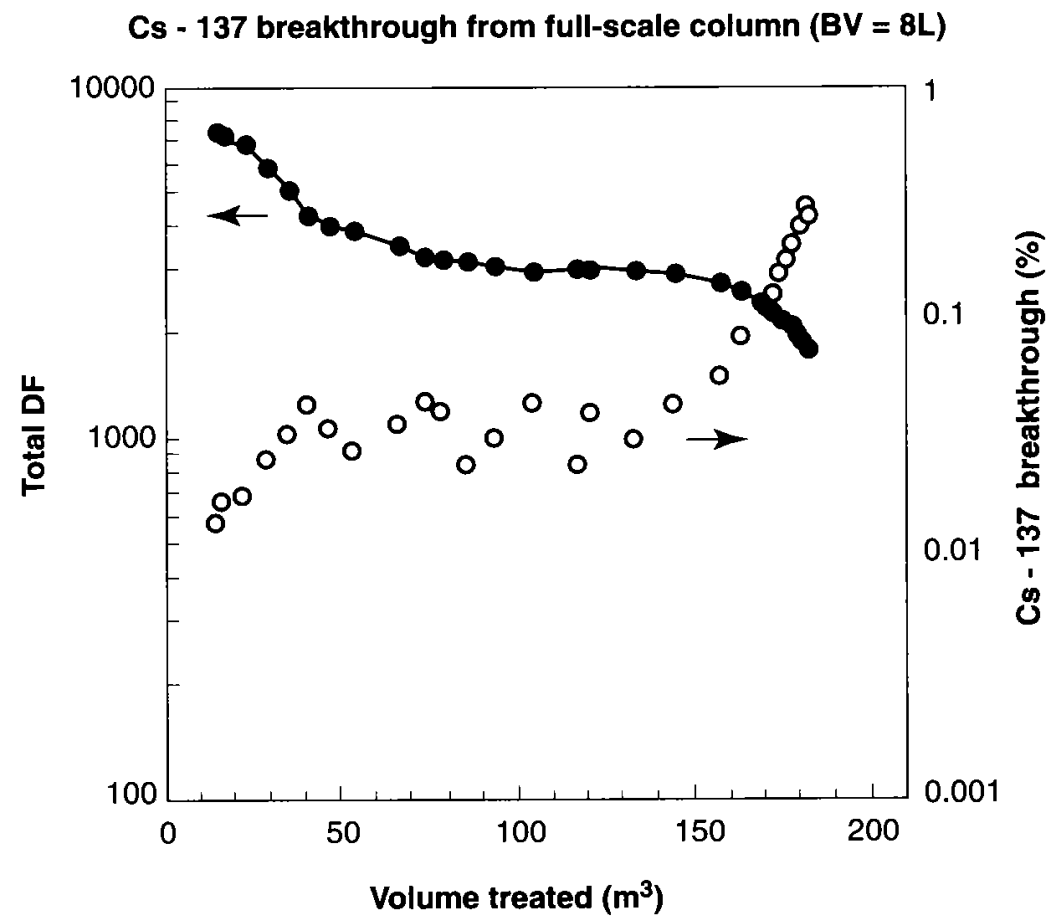

DF : decontamination factor for ${ }^{137} \mathrm{Cs}$. Bed volume : 8 liters. Flow rate : $80 \mathrm{l} / \mathrm{h}$. Hexacyanoferrate grain size 0.8 to $0.3 \mathrm{~mm}$.

Fig. 2. - Performance of an hexacyanoferrate column.

Efficacité d'une colonne d'extraction du cesium chargée en hexacyanoferrate de cobalt. 


\subsection{Removal of Strontium}

In the past years such practices as chemical analysis and development of new technologies have used the unique ability of microcyclic polyethers the so-called crown ethers to bind metal ions with a high selectivity and to change the selectivity of complex formation by changing the cavity size.

On the basis of acrylic acid and mono and dibenzo 18-crown 6, water soluble hydrazides of polyacrylic acid have been obtained which feature a complex forming ability with respect to metal ions including raionuclides ${ }^{51} \mathrm{Cr},{ }^{60} \mathrm{Co}$, ${ }^{106} \mathrm{Ru},{ }^{137} \mathrm{Cs}$ and ${ }^{90} \mathrm{Sr}$.

In systems based on dicyclohexyl 18-crown 6 and fluorine containing diluent, the radionuclide ${ }^{90} \mathrm{Sr}$ is extracted with $90 \%$ efficiency from high activity nitrate waste resulting from reprocessing effluents.

With the same efficiency and from the same waste ${ }^{137} \mathrm{Cs}$ is extracted on the basis of dibenzo l-crown 7 with the use of fluorinated diluent.

The selective Strontium adsorption developed by russian institutes consist of passing the contaminated solution on a column of styrene divinyl benzene copolymer beads impregnated with dicyclohexyl 18-crown 6 in tetrachlorethane. The column is then washed with $1.5 \mathrm{M}$ nitric acid.

The Strontium desorption can be obtained in hot water with proper control of temperature - Based on tests results indicated in Table II and Table III the optimum recovery is achieved by using water at a temperature of $80^{\circ} \mathrm{C}$.

TABLE II

Desorption of 85 Strontium from chromatographic column.

Désorption du strontium 85 d'une colonne chromatographique en pourcentage.

\begin{tabular}{|c|c|c|c|c|c|c|c|}
\hline 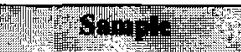 & Y & 2 & 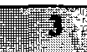 & 18 & 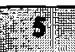 & 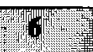 & 7 \\
\hline $\begin{array}{l}\text { Desomption } \\
\text { temperatare }\left({ }^{\circ} \mathrm{C}\right)\end{array}$ & 80 & 70 & 80 & 70 & 70 & 45 & 70 \\
\hline 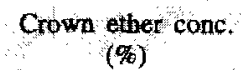 & 5 & 5 & 10 & 10 & 10 & 10 & 10 \\
\hline $\begin{array}{c}\text { Crown ether act vity } \\
\text { (Bq) }\end{array}$ & 5432 & 5731 & 5186 & 6624 & 6508 & 766 & 555 \\
\hline $\begin{array}{l}\text { Water activity } \\
\text { (Bq) }\end{array}$ & 4971 & 4590 & 4704 & 6132 & 5885 & 433 & 500 \\
\hline Yield & 91 & 80 & 91 & 93 & 90 & 57 & 90 \\
\hline
\end{tabular}


TABLE III

Carrier precipitation of Strontium.

Entraînement par précipitation du Strontium.

\begin{tabular}{|ccccccccc|}
\hline \begin{tabular}{c} 
Semple \\
\hline $\begin{array}{c}\text { Table activity } \\
\text { (Bq) }\end{array}$
\end{tabular} & 4900 & 4550 & 4700 & 5325 & 5116 & 430 & 495 \\
$\begin{array}{c}\text { Precipitate activity } \\
\text { (Bq) }\end{array}$ & 4875 & 4518 & 4655 & 5304 & 5070 & 425 & 491 \\
$\begin{array}{c}\text { Yield } \\
(\%)\end{array}$ & 99 & 99 & 98 & $99+$ & 99 & 99 & 99 \\
\hline
\end{tabular}

An impregnation of the beads with 5\% to $10 \%$ dicyclohexyl 18-crown 6 seems to be adequate for a good recovery.

The step of carrier precipitation of strontium oxalate, filtration and subsequent conversion to carbonate is straight forward strontium loss in this step is limited to about $1 \%$ (see Table III).

\section{Large scale removal and purification systems}

\subsection{Selective recovery principles}

In order to develop large purification systems for treating significant quantities of contaminated water, a system combining the selective absorption of radioactive contaminants with a fixation to a magnetic support for the collection on electromagnetic filters could be proposed for large purification units.

The selective recovery of the hazardous or radioactive contaminants can be obtained by engineered particles consisting of magnetic core a polymer coating to enhance the durability and a selective absorber coating.

The selective absorber can either be a resin or a selective obsorbing particle "seeds" (e.g. potassium cobalt hexacyanoferrate) as shown on the Figure 3. The particles can also vary in size from 10 to 100 microns. 


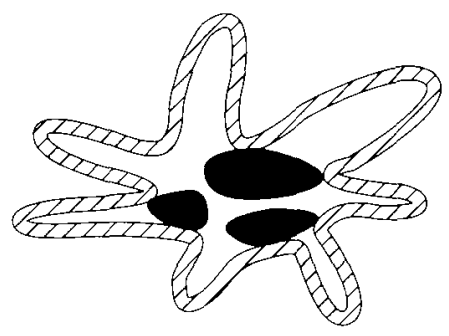

Magnetic particle

Functionalized resin

Non functionalized resin

\section{“Functionalized" particle}

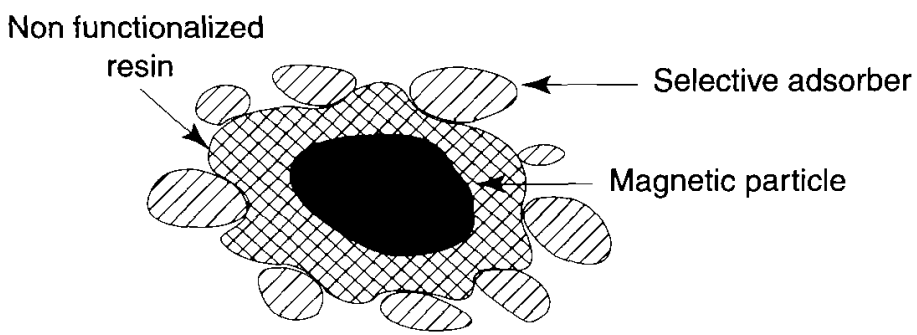

\section{Particle with seeds}

Fig. 3. - MAG SEP particles.

Particules enrobées magnétiques type MAG SEP.

\subsection{Process operation}

The engineered absorbing particles are injected into the process system where they absorb the contaminants and radioactive species.

The particles with contaminants are collected on the magnetic spheres of an electromagnetic filter. Because the particles have a magnetite core they are easily recovered in the presence of other solids at high flow rates.

Periodically the magnetic filter is back washed and the particles and contamination are collected in a recovery tank. The back-wash operation is carried out after demagnetisation of the electromagnetic filter, the back-wash effluent is treated and solidified for permanent disposal.

The particles can be regenerated for reuse or disposed of in a stabilized matrix. If regenerated the contaminants are dissolved into a regenerated solution. The contaminants can be recovered by recycling or volume reduced. Once regenerated the particles are re-used. A general outline of the complete system is given in Figure 4 (in situ water treatment system diagram). 


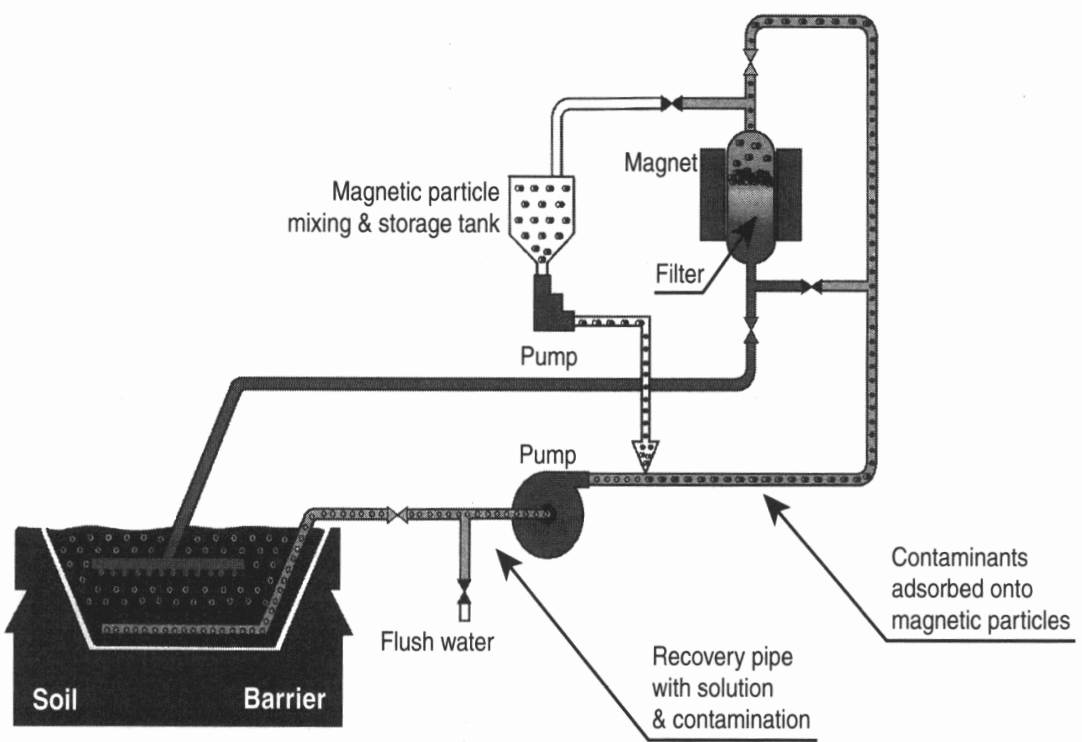

Fig. 4. - In situ water treatment flow diagram.

Schéma de traitement sur site de l'eau contaminée d'un réservoir par épuration magnétique.

\subsection{Electromagnetic filtration and process performance}

For preventing the harmful deposition of contaminants of Nuclear steam systems of reactors, Framatome has developed and qualified an electromagnetic filter (EMF) for application to nuclear reactor (see Fig. 5) at the french nuclear research center of Cadarache.

The Framatome's EMF consists of a pressure vessel containing a matrix of ferritic stainless steel spheres that are magnetized by electromagnetic coils localized externally to the pressure vessel constituing the filter.

Corrosion products and engineering spheres are efficiently removed when fluid containing magnetic particles passes through the sphere matrix. 


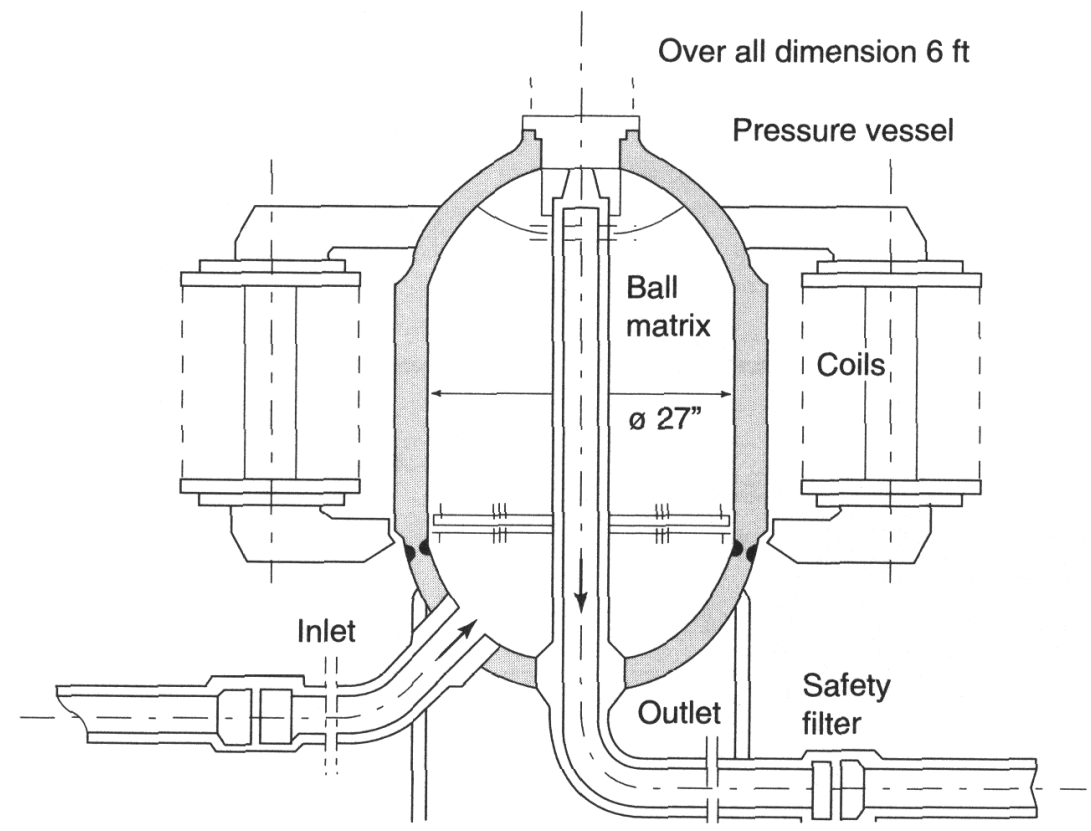

Fig. 5. - Filter design.

Conception du filtre électromagnétique.

Even at low concentration $1 \mathrm{mg} \mathrm{m}^{-3}$ of water $(1 \mathrm{ppb})$ high removal efficiencies between $70 \%$ and $85 \%$ can be achieved as shown on Figure 6.

Endurance testing of an electromagnetic filter carried out on a side arm loop of a naval reactor showing efficient retention of activated corrosion products.

After a predeterminated period of operation, the EMF is isolated from the system and the sphere matrix demagnetized and back washed by connecting the filter capacity to a high pressure flashing tank. 

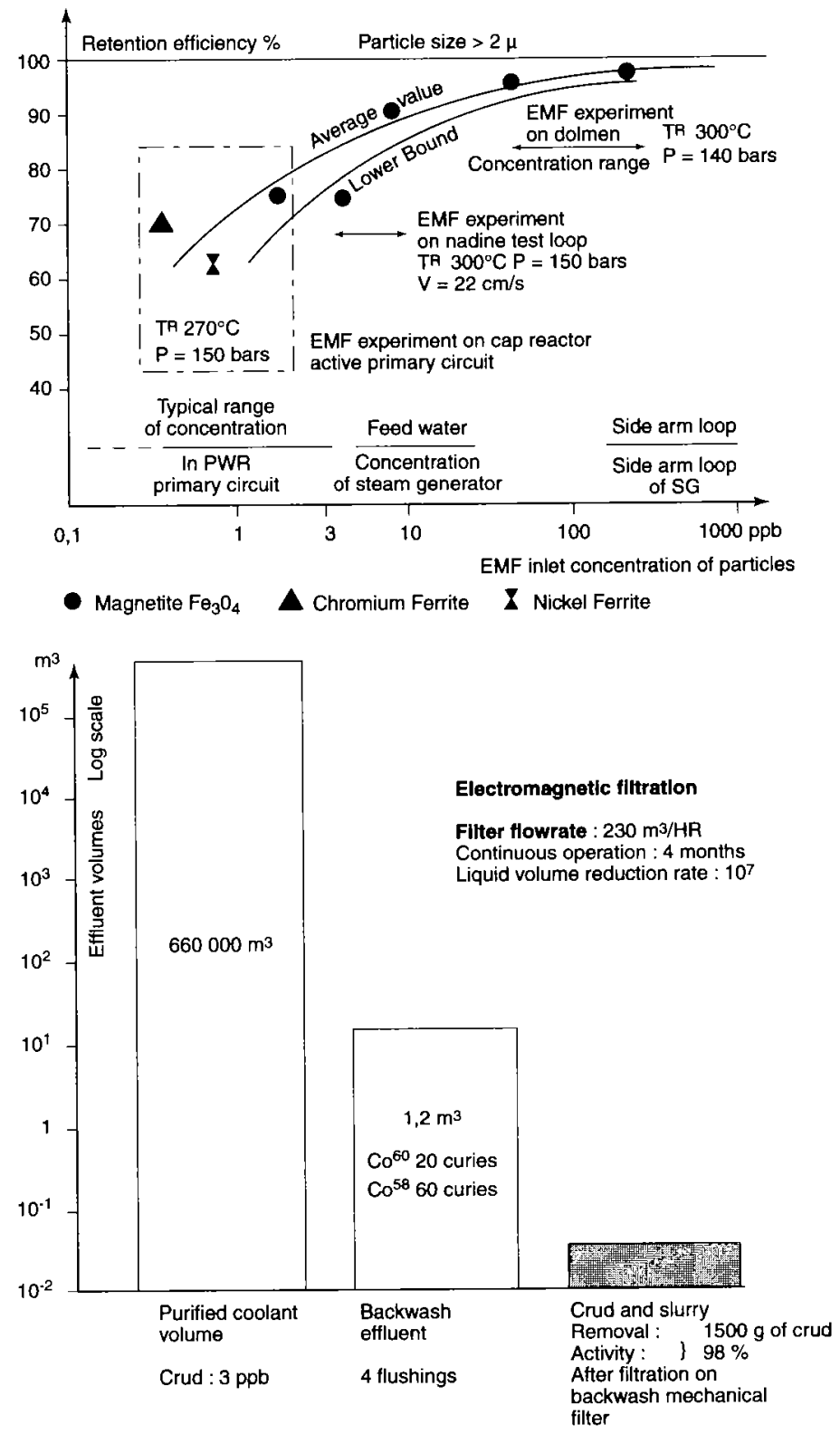

Fig. 6. - Electromagnetic filtration experiments.

Performance de rétention des filtres électromagnétiques. 


\section{Conclusions}

The combination of new developed technologies in association with large flow filtration capabilities given by electromagnetic filtration can help to solve the contamination problem of storage pound of contaminated water localized near the crippled nuclear installations such as the Chernobyl NPP.

However new engineering development has to be established in order to improve the technology of selective absorbent with the already existing technology.

With efficiency removal close to $90 \%$ of contaminant, it is however important to treat the contaminated water as soon as possible in order to prevent harmful deposition of radionuclides on sediments or infiltration of contamination to the groundwater system.

Mobile installation unit can be also built for treating specific problems knowing the contaminants in terms of radionuclides or heavy metals.

\section{RÉFÉRENCES}

Information from Selentec Atlanta.

Lehto J., Harjula R. Separation of cesium from nuclear evaporation concentrates with a hexacyanoferrate ion exchanger. Department of radiochemistry of Helsinki.

Verdoni P., Dubourg M., Arod J., Darras R., Dolle L.(1979) Decontamination and decommissioning of nuclear facilities - ANS Meeting. The french program on electromagnetic filtration. Sun Valley, Idaho.

Zablotsky S.V., Rudak E.A., Stopolyanskaya L.V., Wicley J.R. (1995) Improvements in the method of strontium 10 extraction from environmental samples with dicyclohexyl 18-crown 6 . Kerntechnik 60. 